\title{
МОРФОЛОГИЧЕСКАЯ ХАРАКТЕРИСТИКА КЛИНИЧЕСКОГО СЛУЧАЯ БОЛЕЗНИ БЮРГЕРА
}

Н. С. Цимбалист ${ }^{1 凶}$, Б. А. Суфтинн², А. В. Крючкова'

${ }^{1}$ Российский университет дружбы народов, Москва, Россия

2 Главный военный клинический госпиталь войск национальной гвардии Российской Федерации, Балашиха, Россия

\begin{abstract}
Бюлезнь Бюргера - это достаточно редкая патология, для которой характерно неатерогенное поражение сосудов с формированием в интиме сосуда воспалительного процесса и образованием тромба. Наиболее часто в патологический процесс бывают вовлечены артерии мелкого и среднего калибра. Окклюзия сосудов может привести к ишемии тканей, появлению трофических язв и стать причиной ампутации конечности. На сегодняшний день патогенез заболевания остается до конца неизученным. Литературные данные указывают на то, что развитие патологии может быть связано с аутоиммунными процессами. В статье представлены результаты иммуногистохимического исследования материала, полученного после ампутации нижней конечности у пациента с клиническим диагнозом болезнь Бюргера, имевшего 15-летний стаж курения. В воспалительных клеточных инфильтратах вокруг пораженных сосудов были обнаружены лимфоциты с антигенами CD4, CD8 и депозиты иммуноглобулинов IgG, которые могли служить подтверждением участия аутоиммунных механизмов в развитии заболевания. Иммуногистохимические реакции с маркерами NK-клеток CD56 и главного компонента системы комплемента С3d оказались отрицательными. Полученные результаты позволяют предположить, что основная роль в цепи патогенеза болезни Бюргера принадлежит Т-лимфоцитам-хелперам и супрессорам, а также гуморальным антителам класса IgG.
\end{abstract}

Ключевые слова: болезнь Бюргера, иммуногистохимия, CD4, CD8, IgG

Вклад авторов: И. И. Бабиченко, Б. А. Суфтин - концепция и дизайн исследования; Б. А. Суфтин, Е. А. Чупятова - сбор и обработка материала; Н. С. Цимбалист, А. В. Крючкова, И. И. Бабиченко - написание текста статьи; И. И. Бабиченко - редактирование.

Соблюдение этических стандартов: пациент подписал добровольное информированное согласие на исследование и публикацию материала.

$\triangle$ Для корреспонденции: Наталья Сергеевна Цимбалист

ул. Кусковская, д. 1, кв. 77, г. Москва, 111398; n_zimb@list.ru

Статья получена: 09.12.2019 Статья принята к печати: 15.01.2020 Опубликована онлайн: 23.01.2020

DOI: 10.24075/vrgmu.2020.004

\section{CASE REPORT: MORPHOLOGICAL ASPECTS OF BUERGER'S DISEASE}

\author{
Tsimbalist NS ${ }^{1}$, Suftin BA², Kriuchkova AV'1 , Chupyatova EA¹, Babichenko II
}

${ }^{1}$ Peoples' Friendship University of Russia, Moscow, Russia

${ }^{2}$ Central Military Clinical Hospital of the National Guard Troops of the Russian Federation, Balashikha, Russia

\begin{abstract}
Buerger's disease is a rather rare pathology characterized by nonatherogenic vascular lesion associated with the inflammation in the intima of the vessel and the thrombus formation. Most often the pathological process affects small and medium caliber arteries. Vascular occlusion can lead to tissue ischemia and the trophic ulcers, and cause the extremity amputation. The disorder pathogenesis has not been fully explored. Literature data indicate that the disease development may be associated with autoimmune processes. The paper presents the results of immunohistochemical study of the material obtained after amputation of the lower extremity in a patient diagnosed with Buerger's disease. The patient had a 15-year tobacco smoking experience. In the inflammatory cell infiltrates around the affected vessels, lymphocytes with CD4, CD8 antigens and IgG immunoglobulin deposits were found, which could be considered as the evidence of the autoimmune mechanisms' involvment. Immunohistochemical reactions with markers of NK cells CD56 and the central component of the C3d complement system were negative. The results of the study suggest that the key role is played by helper and suppressor T lymphocytes, as well as by humoral antibodies of the lgG class.
\end{abstract}

Keywords: Buerger's disease, immunohistochemistry, CD4, CD8, IgG

Author contribution: Babichenko II, Suftin BA — study concept and design; Suftin BA, Chupyatova EA — data acquisition and processing; Tsimbalist NS, Kriuchkova AV, Babichenko II - manuscript writing; Babichenko II - manuscript editing.

Compliance with ethical standards: the patient signed the informed consent to the study and publishing of the results.

$\triangle$ Correspondence should be addressed: Natalia S. Tsimbalist Kuskovskaya, 1-77, Moscow, 111398; n_zimb@list.ru

Received: 09.12.2019 Accepted: 15.01.2020 Published online: 23.01.2020

DOI: 10.24075/brsmu.2020.004

Болезнь Бюргера - это редкая патология, которая наиболее широко распространена в странах Восточной Европы и Азии [1]. Характеризующий ее облитерирующий тромбангиит был впервые описан в 1879 г. Феликсом фон Винивартером, в 1908 г. Лео Бюргер опубликовал более подробное описание этой патологии [2-5]. Облитерирующий тромбангиит, или болезнь Бюргера, неатеросклеротическое прогрессирующее заболевание, для которого характерно поражение сосудов мелкого и среднего калибра [2]. В патологический процесс могут быть вовлечены сосуды различной локализации, наиболее часто заболевание поражает артерии конечностей, как правило, бедренную и лучевую. В редких случаях болезнь затрагивает коронарные, сонные и висцеральные артерии [6].
Согласно данным литературы, частота встречаемости заболевания у пациентов с нарушением кровообращения колеблется в пределах 0,5-5\% в Европе, а в Японии этот показатель может достигать 16\% [6]. Заболевание чаще встречается у курящих мужчин [2, 3, 7]. Как правило, болезнь проявляется в возрасте 40-45 лет [4, 8]. В основе патогенеза заболевания может лежать эндотелиальная дисфункция [9]. Под действием повреждающих агентов нарушается проходимость сосудов, возникают воспаление и тромбоз [10]. По данным ряда авторов, к развитию заболевания может приводить патология иммунного гомеостаза.

Известно, что при болезни Бюргера повышается уровень воспалительных цитокинов, высвобождаемых 
иммунными клетками, при этом воспалительная реакция усугубляет тяжесть заболевания [9, 10]. У пациентов с облитерирующим тромбангиитом были выявлены антигены HLA, A28, Ax, B53 и Bx [11]. В плазме крови также отмечали повышение уровня TNF $\alpha$, IL1 $\beta$, IL4, IL17 и IL23. Повышенный уровень IL17 и IL23 указывает на развитие аутоиммунных процессов, вызванных неизвестным антигеном (возможно, компонентом никотина) [10].

K клиническим проявлениям болезни Бюргера относится хромота, со временем появляются изъязвления на пальцах ног и боль в покое [2, 4, 6]. В пораженных конечностях отмечают ощущение холода и снижение чувствительности при прикосновении к коже ступней $[5,12]$. Для подтверждения диагноза необходимо исключить тромбофилию, диабет, эмболию и аутоиммунные заболевания [2, 4].

Лечение облитерирующего тромбангиита заключается в строгом прекращении курения [2, 4, 13]. У пациентов, отказавшихся от курения, наблюдается ремиссия заболевания, что способствует снижению риска ампутации [2]. Пациентам также назначают адъювантные препараты, такие как илопрост, сосудорасширяющие препараты, включающие аналоги простагландина, антагонисты кальциевых каналов, антикоагулянтные и антиагрегантные препараты, в том числе аспирин [5, 10, 13]. Если пациент не прекращает курение табака, болезнь прогрессирует, из-за чего возникает необходимость в ампутации конечностей [14].

В работе описан случай проведения иммуногистохимического исследования пораженных сосудов при болезни Бюргера (облитерирующий тромбоангиит) с целью уточнения клеточного состава воспалительного инфильтрата и выявления депозитов lgG.

\section{Описание клинического случая}

Болезнь Бюргера была выявлена у 36-летнего мужчины с 15-летним стажем курения. Наблюдение вели в течение шести месяцев. В мае 2017 г. пациента внезапно начали беспокоить боли в левой стопе. Ему провели симптоматическое лечение, которое не дало эффекта. В начале июня 2017 г. были зафиксированы усиление болей в левой стопе, похолодание стопы, потемнение кожи пальцев стопы. Пациента госпитализировали, ему провели ампутацию левой стопы по Лисфранку в связи с подострым тромбозом артерий левой голени с развитием острой ишемии III степени. Рана культи стопы не зажила, присутствовали выраженные боли в левой стопе и голени. Были отмечены отеки обеих голеней, развилась сгибательная контрактура левого коленного сустава. Пациент спал в положении сидя. На УЗДГ артерий нижних конечностей была выявлена окклюзия левой передней большеберцовой артерии. Стеноз левой поверхностной бедренной артерии был более 60\%. У пациента развилась сухая гангрена левой нижней конечности, из-за чего ему провели ампутацию на уровне бедра в августе 2017 г. Клинический диагноз - облитерирующий тромбангиит с окклюзией передней большеберцовой артерии слева, XAH IV, сухой некроз ампутационной культи торцевой поверхности мягких тканей левой стопы.

Материал был взят из архива ФГКУЗ «ГВКГ войск национальной гвардии». Для исследования были отобраны блоки с фрагментами ткани из области стопы и голени. Образцы подвергли стандартной обработке (вырезка, подготовка парафиновых блоков, получение срезов, окраска гематоксилином и эозином). Исследование препаратов проводили с использованием микроскопа Axioplan 2 Imaging (Karl Zeiss; Германия), для фотосъемки препаратов пользовались камерой AxioCam ERc5s (Karl Zeiss; Германия).

Для уточнения клеточного состава воспалительного инфильтрата и выявления депозитов IgG было проведено иммуногистохимическое исследование по протоколу Quanto с использованием реагентов универсальной системы визуализации UltraVision Quanto (Thermo Fisher Scientific; США), среди которых конъюгат пероксидазы хрена (HRP) на полимере. Исследование проводили на аппарате Autosteiner 360 (Thermo Fisher Scientific; Великобритания). В качестве антител использовали следующие сыворотки: моноклональные мышиные антитела к CD8 (Cell Marque; США), моноклональные кроличьи антитела к CD4 (Cell Marque; США), поликлональные кроличьи антитела к lgG (Cell Marque; США), моноклональные кроличьи антитела к CD56 (Epitomics; США), моноклональные кроличьи антитела к C3d (Clone SP7, Thermo Fisher Scientific; Великобритания). Время экспозиции антител на каждом срезе составило 20 мин.

При макроскопическом исследовании левой нижней конечности, резецированной на уровне средней и нижней трети бедра, было отмечено отсутствие стопы по линии плюсне-предплюсневых суставов (после ампутации по Лисфранку) с незажившей раной и синесерыми окружающими тканями. Также были найдены обтурирующие тромбы артерий и вен на уровне подколенной артерии. Мышцы голени красно-желтые, бледные. Мышцы на уровне резекции красноватые.

Образцы тканей содержали сосуды из области левого бедра, голени и стопы, они были отобраны в непосредственной близости от гангренозных поражений. При проведении гистологического исследования в области стопы и голени были обнаружены некрозы. Были выявлены смешанные тромбы артерий и вен стопы и голени, местами с реканализацией и организацией, отмечена частичная облитерация просвета сосуда. На рис. 1 представлен поперечный срез артерии стопы, присутствуют внутристеночный и периваскулярный фиброз, участки некроза стенки сосуда. На микрофотографии (рис. 2) представлен поперечный срез артерии голени с организованным тромбом и явлениями реканализации. В сосудах бедра тромботические массы не были обнаружены, однако была отмечена частичная облитерация их просвета. Атеросклеротические бляшки отсутствовали. Смешанные тромбы, участки некроза стенок и частичная облитерация просвета были выявлены в сосудах разного калибра, в

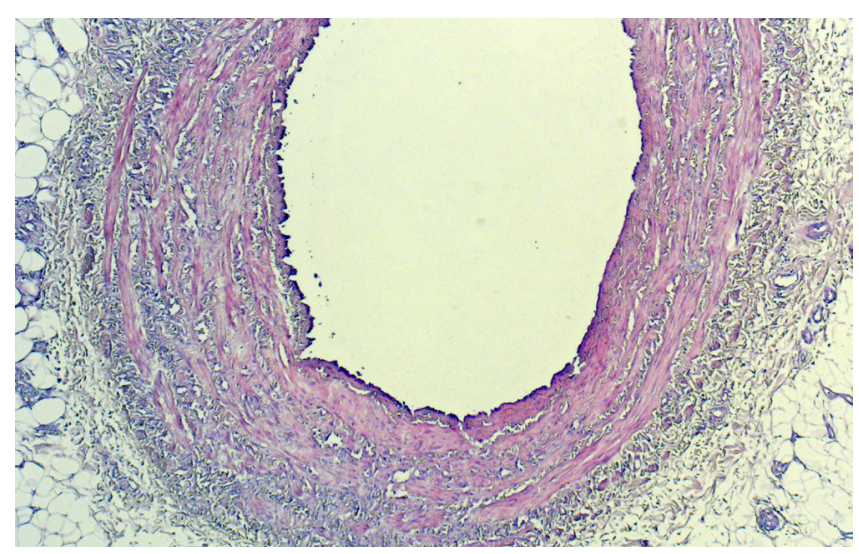

Рис. 1. Поперечный срез артерии стопы. Внутристеночный и периваскулярный фибброз. Микрофотография. Окраска гематоксилином и эозином (х50) 
крупных сосудах также отмечали большое количество vasa vasorum и присутствие лимфоцитов в стенке, из-за чего пациенту был поставлен диагноз облитерирующий тромбангиит.

Материал направили на иммуногистохимическое исследование. Дальнейшее проведение микроскопии показало, что в сосудах малого и среднего калибра, преимущественно в артериолах, имели место положительные цитоплазматические реакции при использовании сывороток к рецепторам маркера субпопуляций Т-лимфоцитов CD4 (преимущественно в стенке артерии голени (рис. 3)) и маркера субпопуляций Т-лимфоцитов CD8 (в стенке сосуда (артериолы) стопы (рис. 4)). На поверхности эндотелия сосудов и в их стенках наблюдали депозиты IgG (рис. 5). Отрицательная реакция была выявлена для сывороток к рецепторам CD56, маркеру NK-клеток, а также для главного компонента активации системы комплемента С3d.

\section{Обсуждение клинического случая}

Патологический процесс при болезни Бюргера начинается в дистально расположенных сосудах, прогрессируя до проксимальных [2]. Основные патологические изменения характеризуются образованием тромбов, внутристеночным и периваскулярным фиброзом кровеносных сосудов [5]. Клинически выделяют три фазы течения болезни: острую, подострую и хроническую [2, 3]. В острой фазе отмечают начало воспаления, проявляющееся в инфильтрации нейтрофилами и окклюзии сосудов тромбом. Стенка сосуда относительно сохранена. В подострой фазе происходит организация тромба с постоянной адгезией тромбоцитов. В хронической фазе на фоне отсутствия медиаторов воспаления наблюдается фриброз сосуда с закупоркой его организованным тромбом. В дальнейшем может возникать реканализация [2]. При выраженных патологических изменениях и появлении язв проводят ампутацию конечности [5, 10]. В качестве лечения применяют эндоваскулярные методы вмешательства, проводят операции, предполагающие шунтирование, резекцию задних большеберцовых вен [13].

В описанном нами клиническом случае пациенту была проведена ампутация из-за развития гангрены левой ноги. При гистологическом исследовании в сосудах были выявлены смешанные тромбы, явления организации и частичная облитерация их просвета.

При постановке диагноза болезнь Бюргера необходимо отличать ее от других заболеваний, связанных с поражением сосудов. Так, при облитерирующем тромбангиите поражение сосудов характеризуется инфильтрацией клетками воспаления всех трех слоев стенки артерии, а при атеросклерозе в патологический процесс вовлечена только интима [2]. Мигрирующий тромбофлебит при болезни Бюргера отличает ее от остальных ангиитов. Основные гистологические признаки заболевания - это гиперплазия интимы сосудов наподобие капиллярного ангиоматоза, закупорка сосудов тромботическими массами, отсутствие кальцификации средней оболочки и панфлебит в венах [13].

Полученные нами результаты подтверждают, что основные патологические изменения при болезни Бюргера - это тромбоз сосудов артериального типа с наличием воспалительной инфильтрации во всех трех слоях стенки с гиперплазией интимы при отсутствии признаков атеросклероза. По данным ряда авторов [3],

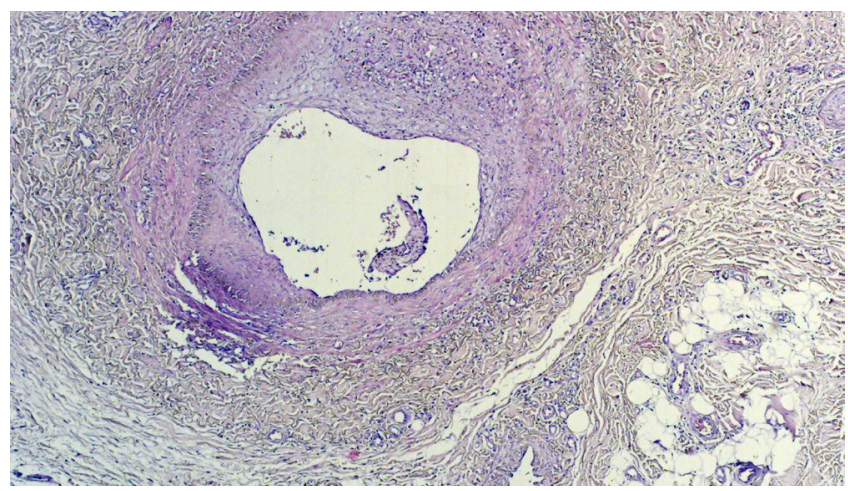

Рис. 2. Поперечный срез артерии голени. Организованный тромб с реканализацией. Микросротографияя. Окраска гематоксилином и эозином (х50)

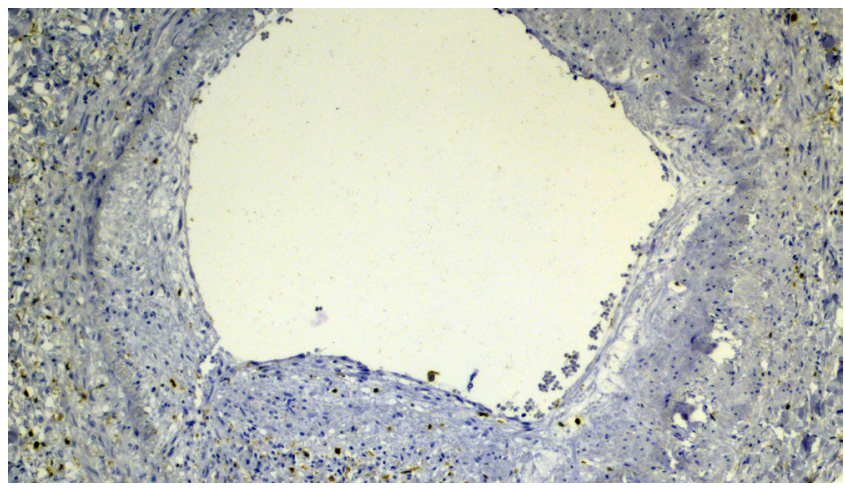

Рис. 3. Артерия голени. Иммуногистохимическая реакция с антителами к белку CD4: цитоплазматическая локализация маркера. Микрофотография. Окраска ДАБ-гематоксилином (х100)

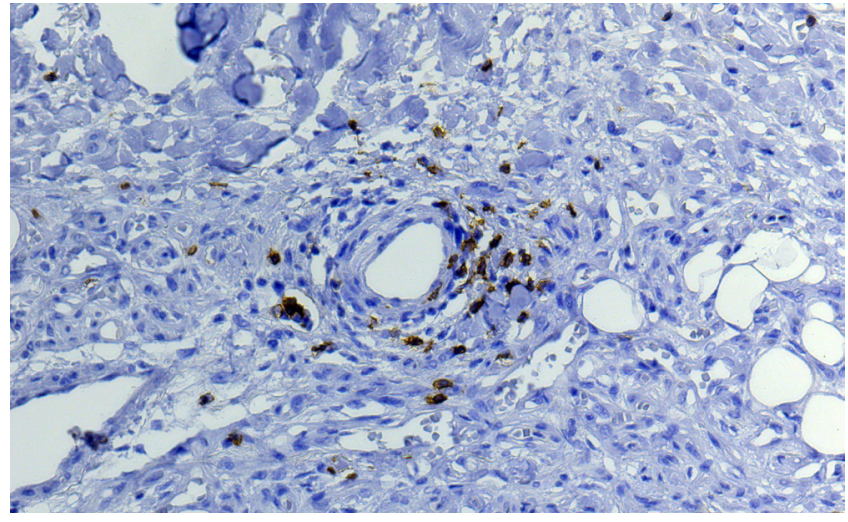

Рис. 4. Артериола стопы. Иммуногистохимическая реакция с антителами к белку CD8: цитоплазматическая локализация маркера. Микрофотография. Окраска ДАБ-гематоксилином (х200)

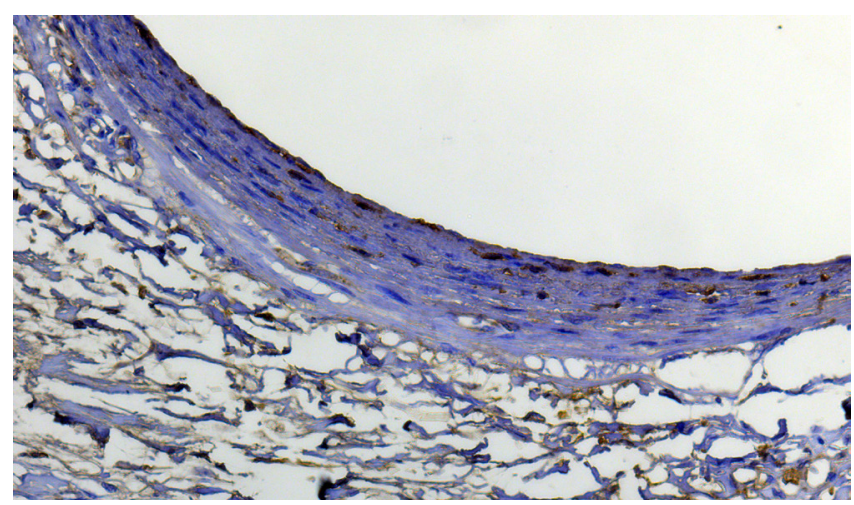

Рис. 5. Артерия стопы. Иммуногистохимическая реакция с антителами к белку IgG: локализация маркера на эндотелии. Микрофоотография. Окраска ДАБ-гематоксилином (х200) 
начало и сохранение воспалительного ответа зависит от целостности эндотелия - при эндотелиальной дисфункции нарушается эндотелий-зависимая вазорелаксация. В нашем исследовании на поверхности эндотелия и в стенке сосуда были обнаружены депозиты lgG.

В работе [10] показано повышение уровня провоспалительных цитокинов IL1 $\beta$, TNF $\alpha$ и IL6 в плазме пациентов с болезнью Бюргера, а также повышение уровня цитокинов Th1 (IFN $\gamma$ и IL12). В отношении цитокинов Th2 показаны увеличение IL4, IL5 и IL13 и снижение IL10, а также увеличение цитокиновых профилей Th17 (IL17 и IL23), указывающих на вовлечение аутоиммунных механизмов. Группой авторов [2] было выдвинуто предположение, что у пациентов с болезнью Бюргера могут присутствовать специсический клеточный иммунитет к артериальным антигенам и гуморальные антиартериальные антитела и иммунные комплексы.

В работе [15] приведены результаты исследования иммуногистохимическим методом образцов ткани, полученных из артерии dorsalis pedis с целью обнаружения новых антигенов, которые могут отвечать за местные воспалительные реакции и структурные изменения при облитерирующем тромбангиите. Были определены такие антигены, как CD34, CD44 и CD90. Исследователи предполагают, что пара рецептор/лиганд CD90/CD11c играет важную роль в привлечении мононуклеарных клеток к месту повреждения.

В нашем случае образцы тканей были взяты из ампутированной конечности (стопы, голени и бедра) у пациента с клиническим диагнозом болезнь Бюргера, имевшего 15-летний стаж курения. Были определены клетки, несущие маркеры, которые могут указывать на вовлечение иммунного звена в патогенез болезни - CD4, CD8, а также депозиты lgG.

\section{ВЫВОДЫ}

Результаты исследования позволяют предположить, что в развитии заболевания участвуют аутоимунные механизмы, при этом ключевая роль принадлежит Т-лимфоцитамхелперам и супрессорам, а также гуморальному иммунитету за счет IgG.

\section{Литература}

1. Shionoya S, Leu HJ, Lie JT. Buerger's disease (thromboangiitis obliterans). In: Stehbens WE, Lie JT, eds. Vascular pathology. London: Chapman \& Hall Medical, 1995; p. 657-78.

2. Qaja E, Fortune MA. Buerger Disease (Thromboangiitis Obliterans). StatPearls [Internet]. 2019 Nov [cited 2019 Nov 11]; [about 3 p.]. Available from: https://www.statpearls.com/sp/rn/18685/.

3. Rivera-Chavarría IJ, Brenes-Gutiérrez JD. Thromboangiitis obliterans (Buerger's disease). Ann Med Surg (Lond). 2016; (7): 79-82. PubMed PMID: 27144003.

4. Seebald J, Gritters L. Thromboangiitis obliterans (Buerger disease). Radiol Case Rep. 2015; 10 (3): 9-11. PubMed PMID: 26649109.

5. Li Q-L, He D-H, Huang Y-H, Niu M. Thromboangiitis obliterans in two brothers. Experimental and Therapeutic Medicine. 2013; 6 (2): 317-20. PubMed PMID: 24137181

6. Nobre CA, Vieira WP, da Rocha FE, de Carvalho JF, Rodrigues CE. Clinical, arteriographic and histopathologic analysis of 13 patients with thromboangiitis obliterans and coronary involvement. Isr Med Assoc J. 2014; 16 (7): 449-53. PubMed PMID: 25167694.

7. Шилкина Н. П., Лилеева М. А., Дряженкова И. В., Каусрман Е. В., Прокопенко А. В. Облитерирующий тромбангиит и атеросклероз сосудов нижних конечностей: клинико-морфологическая характеристика. Клиническая геронтология. 2006; 12 (2): 15-18.

8. Elfarra M, Rădulescu D, Peride I, Niculae A, Ciocâlteu A, Checheriță IA, et. al. Thromboangiitis obliterans - case report. Chirurgia (Bucur). 2015; 110 (2): 183-7. PubMed PMID: 26011844.

9. Igari K, Kudo T, Toyofuku T, Inoue Y. Endothelial dysfunction in

\section{References}

1. Shionoya S, Leu HJ, Lie JT. Buerger's disease (thromboangiitis obliterans). In: Stehbens WE, Lie JT, eds. Vascular pathology. London: Chapman \& Hall Medical, 1995; p. 657-78.

2. Qaja E, Fortune MA. Buerger Disease (Thromboangiitis Obliterans). StatPearls [Internet]. 2019 Nov [cited 2019 Nov 11]; [about 3 p.]. Available from: https://www.statpearls.com/sp/rn/18685/.

3. Rivera-Chavarría IJ, Brenes-Gutiérrez JD. Thromboangiitis obliterans (Buerger's disease). Ann Med Surg (Lond). 2016; (7): 79-82. PubMed PMID: 27144003.

4. Seebald J, Gritters L. Thromboangiitis obliterans (Buerger disease). Radiol Case Rep. 2015; 10 (3): 9-11. PubMed PMID: 26649109.

5. Li Q-L, He D-H, Huang Y-H, Niu M. Thromboangiitis obliterans in two brothers. Experimental and Therapeutic Medicine. 2013; 6 (2): 317-20. PubMed PMID: 24137181.

6. Nobre CA, Vieira WP, da Rocha FE, de Carvalho JF, Rodrigues CE. Clinical, arteriographic and histopathologic analysis of 13 patients with thromboangiitis obliterans and coronary involvement. Isr Med Assoc J. 2014; 16 (7): 449-53. PubMed PMID: 25167694.

7. Shilkina NP, Lileeva MA, Drjazhenkova IV, Kaufman EV, Prokopenko AV. Obliterirujushhij trombangiit i ateroskleroz sosudov nizhnih konechnostej: kliniko-morfologicheskaja harakteristika. Klinicheskaja gerontologija. 2006; 12 (2): 15-18.

patients with Buerger disease. Vasc Health Risk Manag. 2017; (13): 317-23. PubMed PMID: 28860792.

. Dellalibera-Joviliano R, Joviliano EE, Silva JS, Evora PR. Activation autoimmunity in thromboangiitis obliterans patients. Clin Exp Immunol. 2012; 170 (1): 28-35. PubMed PMID: 22943198.

11. Schmitt J, Schmidt C, Alan C, Haller C, Perrier P. Population genetics, immunologic evaluation and Buerger's disease. Projection through a personal study comprising 127 cases of juvenile arteriopathy. Bull Acad Natl Med. 1993; 177 (7): 1153-64. PubMed PMID: 8149255.

2. Wan J, Yang Y, Ma ZH, Sun Y, Liu YQ, Li GJ, et al. Autologous peripheral blood stem cell transplantation to treat thromboangiitis 20 (3): 509-13. PubMed PMID: 26914127.

13. Зербино Д. Д., Зимба Е. А., Багрий Н. Н. Облитерирующий тромбангиит (болезнь Бюргера): современное состояние проблемы. Ангиология и сосудистая хирургия. 2016; 22 (4): 185-92.

14. Sinclair NR, Laub DR. Thromboangiitis Obliterans (Buerger's Available from: http://www.eplasty.com/interesting-cases/3591thromboangiitis-obliterans-(buerger's-disease)

15. Guzel E, Topal E, Yildirim A, Atilla P, Akkus M, Dagdeviren A. Targeting novel antigens in the arterial wall in thromboangiitis obliterans. Folia Histochem Cytobiol. 2010; 48 (1): 134-41. PubMed PMID: 20529829. 
8. Elfarra M, Rădulescu D, Peride I, Niculae A, Ciocâlteu A, Checheriță IA, et. al. Thromboangiitis obliterans - case report. Chirurgia (Bucur). 2015; 110 (2): 183-7. PubMed PMID: 26011844.

9. Igari $\mathrm{K}$, Kudo T, Toyofuku T, Inoue $\mathrm{Y}$. Endothelial dysfunction in patients with Buerger disease. Vasc Health Risk Manag. 2017; (13): 317-23. PubMed PMID: 28860792.

10. Dellalibera-Joviliano R, Joviliano EE, Silva JS, Evora PR. Activation of cytokines corroborate with development of inflammation and autoimmunity in thromboangiitis obliterans patients. Clin Exp Immunol. 2012; 170 (1): 28-35. PubMed PMID: 22943198.

11. Schmitt J, Schmidt C, Alan C, Haller C, Perrier P. Population genetics, immunologic evaluation and Buerger's disease Projection through a personal study comprising 127 cases of juvenile arteriopathy. Bull Acad Natl Med. 1993; 177 (7): 1153-64. PubMed PMID: 8149255.
12. Wan J, Yang Y, Ma ZH, Sun Y, Liu YQ, Li GJ, et al. Autologous peripheral blood stem cell transplantation to treat thromboangiitis obliterans: preliminary results. Eur Rev Med Pharmacol Sci. 2016; 20 (3): 509-13. PubMed PMID: 26914127.

13. Zerbino DD, Zimba EA, Bagrij NN. Obliterirujushhij trombangiit (bolezn' Bjurgera): sovremennoe sostojanie problemy. Angiologija i sosudistaja hirurgija. 2016; 22 (4): 185-92.

14. Sinclair NR, Laub DR. Thromboangiitis Obliterans (Buerger's Disease). Eplasty [Internet]. 2015 [cited 2015 Apr 10]; [about 6 p.]. Available from: http://www.eplasty.com/interesting-cases/3591thromboangiitis-obliterans-(buerger's-disease)

15. Guzel E, Topal E, Yildirim A, Atilla P, Akkus M, Dagdeviren A. Targeting novel antigens in the arterial wall in thromboangiitis obliterans. Folia Histochem Cytobiol. 2010; 48 (1): 134-41. PubMed PMID: 20529829. 